\title{
LA PROTECCIÓN JURÍDICO-CONSTITUCIONAL DEL DERECHO A LA IDENTIDAD EN EL PERÚ: RESPUESTAS FRENTE AL COVID-19
}

\author{
THE LEGAL-CONSTITUTIONAL PROTECTION OF THE RIGHT TO \\ IDENTITY IN PERU: RESPONSES TO COVID-19
}

\author{
Carlos Antonio Agurto Gonzáles ${ }^{\mathrm{I}}$ \\ María-Pía Guadalupe Díaz Díaz ${ }^{\text {II }}$
}

${ }^{\text {I } U n i v e r s i d a d ~ N a c i o n a l ~ M a y o r ~ d e ~ S a n ~}$ Marcos, Lima, Peru. Doutorando en Direito.

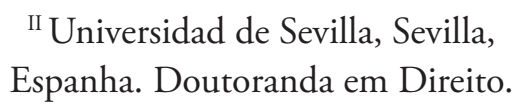

DOI: http://dx.doi.org/10.20912/rdc.v16i38.264

Recebido em: 02.10.2020

Aceito em: 02.01.2021
Resumen: El derecho a la identidad en el Perú se ha consolidado gracias al desarrollo jurisprudencial del Tribunal Constitucional, el cual tiene como antecedente la importantísima doctrina del profesor Carlos Fernández Sessarego. Tal es así que se ha logrado un reconocimiento constitucional del derecho a la identidad como aquel compuesto por elementos estáticos y dinámicos. En esa línea se ha establecido que el sexo es un elemento dinámico de la identidad y, por ende, puede ser modificado, de tal manera que responda a la identidad psicosocial de la persona. La jurisprudencia constitucional peruana ha atendido al llamado de emergencia de una población minoritaria e históricamente discriminada como es la población trans en el Perú, devolviéndoles la protección jurídica a través del conocimiento judicial de las causas referidas al cambio de la mención del sexo en los registros. En este ensayo, se analiza el derecho a la identidad personal de las personas trans, cuya protección jurídica ha sido afectada por la pandemia del COVID-19, lo que nos permite analizar lo que hace falta por desarrollar en cuanto a la efectiva protección de este derecho.

Palabras clave: Covid-19; identidad personal; identidad de género; personas trans.

Abstract: The right to identity in Peru has been
consolidated thanks to the jurisprudential development
of the Constitutional Court, which has as a precedent the
very important doctrine of Professor Carlos Fernández
Sessarego. So much so that a constitutional recognition of
the right to identity has been achieved, such as that made
up of static and dynamic elements. Along these lines,
it has been established that sex is a dynamic element of
identity and therefore can be modified, in such a way that
it responds to the psychosocial identity of the person. The
Peruvian constitutional jurisprudence has responded to the
emergency call of a minority and historically discriminated
population such as the trans population in Peru, restoring 
legal protection to them through judicial hearing of the cases related to the change of the mention of sex in the records. In this essay, the right to personal identity of trans people is analyzed, whose legal protection has been affected by the COVID-19 pandemic, which allows us to analyze what needs to be developed in terms of the effective protection of this law.

Keywords: Covid-19; personal identity; gender identity; trans people.

\section{Introducción}

La pandemia del coronavirus COVID-19 (acrónimo del inglés coronavirus disease 2019) representa uno de los principales desafíos que enfrenta la humanidad en las últimas décadas. La cantidad de personas infectadas, fallecidas, perjudicadas, ha puesto en jaque todo el sistema planetario, y que hace recordar épocas oscuras como la peste negra medieval o la gripe española. Los Estados intentan realizar medidas para frenar o aletargar los efectos nocivos de la enfermedad, no obstante, el enemigo invisible aún se resiste a frenar sus pasos.

Con la finalidad de evitar los contagios masivos de este virus y ante la inobservancia de la población sobre las recomendaciones brindadas para ello, el Estado peruano adoptó diversas estrategias sobre la marcha, una de ellas fue el Decreto Supremo N 057-2020-PCM, de 2 de abril de 2020. A través de esta disposición se restringió la circulación de las personas por determinados días de la semana de forma diferenciada por sexos, es decir para hombres y mujeres, siguiendo, a primera lectura, un modelo estático sobre la identidad, que terminó afectando a las personas trans (transgénero y transexuales) en su aplicación. Si bien la referida norma fue dejada de lado por el ejecutivo, puso en el escenario el debate sobre los alcances del derecho fundamental a la identidad personal.

El presente ensayo tiene por objeto examinar este derecho a la luz de los desarrollos realizados a nivel de la doctrina jurídica, como su evolución en la jurisprudencia del Tribunal Constitucional del Perú y la postura de la Corte Interamericana de Derechos Humanos, para finalmente llamar la atención sobre la necesidad de una ley de identidad de género, que pueda tutelar plenamente este derecho existencial de la persona.

\section{La concepción jurídica derecho a la identidad personal}

La persona es única, no obstante ser igual a todas las demás. En efecto, la persona, cada persona, es idéntica a sí misma. Ello es posible por el hecho de que su ser es ser libertad'. La identidad personal supone ser uno mismo y no otro. La identidad del ser humano, en cuanto ser libre, se constituye en su dimensión dinámica mediante un continuo proceso autocreativo, mediante una sucesión de aspectos en que consiste la existencia, así como por la adhesión a

1 Fernández Sessarego, Carlos, "Un nuovo modo di fare Diritto", en: AA.VV., Il diritto dei nuovi mondi, atti del Convegno promosso dall'Istituto di Diritto Privato delle Facoltà di Giurisprudenza Genova, 5-7 novembre 1992, Cedam, Padua, 1994, p.231. 
na determinada concepción del mundo. Es la "verdad personal", el derecho a ser uno mismo². La identidad personal no es sino la síntesis de la historia vital de cada persona ${ }^{3}$, que permite reconocerse en el vivir comunitario. Es la exigencia de ser uno mismo ${ }^{4}$. No solo se constituye por los datos objetivos, sino también por la proyección social de la vida de la persona ${ }^{5}$.

El sujeto, la persona, libra una guerra civil consigo mismo para afirmar y reafirmar su identidad personal, dentro de la gama de las relaciones sociales-comunitarias. Es, como afirmaba el Prof. Carlos Fernández Sessarego, padre de este derecho existencial en América Latina, un incesante combate, una lucha, con la finalidad que se le considere por los demás como tal, como verdaderamente es, sin desnaturalizaciones ni deformaciones ${ }^{6}$. La identidad es una compleja y constante lucha para afirmar que soy yo y evitar caer en la multiplicidad de circunstancias y situaciones en las que cada persona tendría que expresar que no soy yo mismo, debido a que el ser humano no es una máquina, ni un autómata, sino un ente que se hace, deviene en toda su existencia”.

Es, en palabras de uno de los juristas italianos que más ha estudiado este derecho, Adriano de Cupis, el derecho a ser uno mismo, con nuestras propias características y acciones, que se constituye en la verdad de la persona, que no puede, en sí y por sí, ser destruida: que la verdad, por ser precisamente así, no puede ser eliminada ${ }^{7}$. En esa línea, otro sector importante de la doctrina italiana (la experiencia jurídica en Europa donde más se ha ahondado sobre la materia), ha señalado que el derecho a la identidad personal es el derecho por el cual los aspectos del sujeto y de su vida sean tutelados en atención al principio de verdad, evitando sus distorsiones ${ }^{8}$. En tal sentido, la identidad personal consiste en ser uno mismo y no otro, pese a su integración social. Este perfil de la existencia, que es la mismidad del ser, se erige como un primordial interés personal que exige la protección jurídica, al lado y de la misma forma que sucede con otros intereses fundamentales de la persona, como son la vida o la libertad ${ }^{9}$. Tratar sobre el derecho a la identidad personal implica necesariamente hacer referencia de los desarrollos realizados por la cultura jurídica italiana, que fue la fuente de primordial para que Carlos Fernández Sessarego desarrollada su teoría sobre el referido derecho ${ }^{10}$, por lo que trataremos algunos de los aportes peninsulares sobre la materia.

2 Pino, Giorgio, Il diritto all'identità personale. Interpretazione costituzionale e creatività giurisprudenziale, Il Mulino, Bolonia, 2003, pág. 9.

3 Zeno-Zencovich, Vincenzo, "Identità personale", en: Digesto delle Discipline Privatistiche-Sezione Civile, volumen IX, Utet, Turín, 1993, pág. 294.

4 Dogliotti, Massimo, "I. Le persone fisiche", en: Trattato di Diritto Privato, dirigido por Pietro Rescigno, tomo primo, 2. Persone e famiglia, Utet, segunda edición, Turín, 1999, pág. 146.

5 Finocchiaro, Giusella, "Identità personale (diritto alla)", en: Digesto delle Discipline Privatistiche-Sezione Civile, Aggiornamento, Turín, 2010, pág.725.

6 Fernández Sessarego, Carlos, "El derecho a la identidad personal", en: Tendencias actuales y perspectivas del derecho privado y el sistema jurídico latinoamericano, ponencias presentadas en el Congreso Internacional celebrado en Lima del 5 al 7 de setiembre de 1988, organizado por el Ilustre Colegio de Abogados de Lima y la Associazione di Studi Sociali Latinoamericani (ASSLA), Cultura Cuzco S.A., Lima, 1990, pág. 61.

7 De Cupis, Adriano, I diritti della personalità, segunda edición revisada y actualizada, Trattato di Diritto Civile e Commerciale, già diretto da Antonio Cicu e Francesco Messineo, continuato da Luigi Mengoni, Giuffrè editore, Milán, 1982, pág. 399.

8 Torrente, Andrea y Schlesinger, Piero, Manuale di diritto privato, vigésima tercera edición, al cuidado de Franco Anelli y Carlo Granelli, Giuffrè Francis Lefebvre, Milán, 2019, pág. 148.

9 Fernández Sessarego, Carlos, "El derecho a la identidad personal", en: Nuevas Tendencias en el derecho de las personas, Universidad de Lima, Lima, 1990, pág. 148.

10 Fernández Sessarego, Carlos, Derecho a la identidad personal, segunda edición actualizada y ampliada, Instituto 


\section{La influencia italiana en la construcción del derecho a la identidad personal}

El derecho a la identidad personal en la experiencia italiana ha sido considerado como emergente, un nuevo derecho fundamental del sujeto, el producto de la jurisprudencia madurada a partir de la segunda mitad de los ańos setenta del siglo pasado ${ }^{11}$.

Se puede encontrar que, ya en los ańos cincuenta y sesenta, comienza a evidenciarse una tendencia a superar la visión restrictiva, estática de la identidad, a favor de una perspectiva más amplia $^{12}$. En esta impronta se puede encontrar, como una de las figuras mayores, a Adriano de Cupis (fallecido el 21 de octubre de 2005). Para este jurista el derecho a la identidad personal tiene por objeto un bien que constituye una cualidad, el modo de ser de la persona: la forma de ser uno mismo, que comprende también su relación con la sociedad, la comunitaria, donde vive ${ }^{13}$.

De acuerdo al planteamiento de De Cupis, el centro de la identidad personal es el interés de la persona en aparecer, en el plano social, como realmente es, por lo que la tutela de la identidad personal se realiza a través de la atribución a la persona del derecho al uso exclusivo de ciertos signos distintivos (nombre, pseudónimo, por ejemplo) ${ }^{14}$, en forma de excluir posibles confusiones con otros miembros de la sociedad. Así el derecho a la identidad personal es un derecho subjetivo de la persona, esencial e innato, de alcance general, y que encuentra su aplicación particular en la imagen, nombre, seudónimo y el derecho de rectificación. El interés de este derecho no es solo la identificación erga omnes de la persona, sino también a la representación social del sujeto, el interés por el cual la expresión personal no sea cambiada mediante la atribución incorrecta de determinados hechos o situaciones relacionados con su vida ${ }^{15}$.

Dejando de lado posiciones de perplejidad sobre la existencia de este derecho ${ }^{16}$, la evolución de su concepción jurídica de la identidad personal en la cultura jurídica italiana se consolidó entre los fines de la década de los setenta y el inicio de los ochenta del siglo XX, como consecuencia de la evolución jurisprudencia. Como bien anota Giorgio Pino ${ }^{17}$, de la primigenia consideración de la identidad como suma de signos distintivos, y por ende como individualidad fisica de la persona en el ámbito de un determinado contexto social, la doctrina italiana arriba a la noción de identidad como individualidad personal, vale decir como imagen social que el sujeto proyecta de sí mismo respecto al conjunto de las ideas, de las convicciones, de las posiciones políticas y todo lo que constituya expresión externa del patrimonio del sujeto. Como es evidente, esto representa un salto de calidad, lo que llevó al profesor Pietro Rescigno a declarar que puede encontrar menores aversiones y desconfianzas y puede servir para proporcionar una

Pacífico, Lima, 2015, pág. 52.

11 Pino, Giorgio, Il diritto allidentità personale. Interpretazione costituzionale e creatività giurisprudenziale, pág. 35.

12 Trucco, Laura, Introduzione allo studio dell'identità individuale nell'ordinamento costituzionale italiano, G. Giappichelli Editore, Turín, 2004, pág. 208.

13 De Cupis, Adriano, I diritti della personalità, p. 403.

14 Pino, Giorgio, Il diritto allidentità personale. Interpretazione costituzionale e creatività giurisprudenziale, pág. 35.

15 Pino, Giorgio, Il diritto all'identità personale. Interpretazione costituzionale e creatività giurisprudenziale, pág. 36.

16 Falzea, Angelo, "Il dirtto all'identità personale: motivi di perplessită", en: AA.VV., La lesione dellidentità personale e il danno non patrimoniale, Giuffrè editore, Milán, 1985, pág. 88.

17 Pino, Giorgio, Il diritto allidentità personale. Interpretazione costituzionale e creatività giurisprudenziale, pág. 42. 
respuesta positiva al problema que aquí ha emergido, de conciliar la pretensión del individuo a ver garantizada su identidad ${ }^{18}$.

Se ha considerado que la moderna perspectiva del derecho a la identidad personal inicia una nueva estación en la tutela jurídica de la persona ${ }^{19}$, diferenciándolo de sus manifestaciones particulares (especialmente el nombre).

A nivel jurisprudencial, fue la precursora sentencia del Pretor de Roma del 6 de mayo de1974, el acta bautismal del reconocimiento del derecho a la identidad personal en Italia ${ }^{20}$. En esta sentencia se llega a declarar que "el ordenamiento jurídico tutela el derecho de cada uno a no ser desconocida la paternidad de las propias acciones y, especialmente, no atribuirse la paternidad de actos no suyos, y no ser alterada la propia personalidad individual" ${ }^{21}$. En tal sentido, el derecho a la identidad personal es el derecho de cada persona a ser representada, en la realidad social y en sus relaciones personales, con su verdadera esencia, así como es conocida en el contexto en que vive y desarrolla su vida ${ }^{22}$. Por ello, anotaba magistralmente un jurista tan agudo como fue Stefano Rodotà23 ${ }^{23}$ que la identidad personal es un cuestión abierta en el tiempo.

Otro de los pasajes neurálgicos del reconocimiento jurisprudencial del derecho a la identidad fue la sentencia n ${ }^{\circ}$ 3769, emitida en la Corte de Casación del 22 de junio de 1985. En este pronunciamiento la suprema magistratura manifestó que: "Cada sujeto tiene interés, considerado generalmente merecedor de tutela jurídica, de ser representado, en la vida de relación, con su verdadera identidad, así como esta en el realidad social, general y particular, es conocida o podía ser conocida con los criterios de la normal diligencia y de la buena fe subjetiva; es decir, tiene interés en no verse al exterior alterado, cambiado, en el contexto de su patrimonio intelectual, político, social, religioso, ideológico, profesional, etc." ${ }^{24}$

También la Corte Constitucional de Italia, mediante sentencia ${ }^{\circ} 13$ del 3 de febrero de 1994 estableció que el derecho a la identidad personal constituye un bien por sí mismo, independientemente de la condición personal y social, de las virtudes y de los defectos del sujeto, por lo que se le reconoce el derecho a que su individualidad sea preservada ${ }^{25}$.

\section{La teoría de Carlos Fernández Sessarego: la doble vertiente de la identidad personal}

El derecho a la identidad personal era prácticamente desconocido tanto en el Perú como en el resto de países latinoamericanos a la década de los años ochenta del siglo XX. Es sólo

18 Rescigno, Pietro, "Conclusioni”, en: Alpa, Guido; Bessone, Mario y Boneschi, Luca (al cuidado de), Il diritto alla identità personale, Cedam, Padua,1981, pág. 189.

19 Pino, Giorgio, Il diritto all'identità personale. Interpretazione costituzionale e creatività giurisprudenziale, pág. 43.

20 Pino, Giorgio, Il diritto all'identità personale. Interpretazione costituzionale e creatività giurisprudenziale, pág. 65 .

21 Citada por Gambaro, Antonio, "Diritti della personalità", en: Rivista di Diritto Civile, parte II, Cedam, Padua, 1981, pág. 519.

22 Nivarra, Luca; Ricciuto, Vincenzo y Scognamiglio, Claudio, Diritto privato, G. Giappichelli editore, quinta edición, Turín, 2019, pág. 171.

23 Rodotà, Stefano, Diritto d'amore, Editori Laterza, Bari, 2017, p.128.

24 Pino, Giorgio, Il diritto all'identità personale. Interpretazione costituzionale e creatività giurisprudenziale, pág. 79.

25 Pino, Giorgio, Il diritto all'identità personale. Interpretazione costituzionale e creatività giurisprudenziale, pág. 95. 
en la última década del referido siglo donde aparecen los primeros desarrollos doctrinarios y jurisprudenciales de este derecho que, junto con el derecho a la vida y el derecho a la libertad, constituye el núcleo de los derechos fundamentales de la persona. Es el libro del recordado maestro peruano Carlos Fernández Sessarego (Callao, 06 de marzo de 1926-Lima, 28 de julio de 2019) Derecho a la identidad personal, publicado por Astrea de Buenos Aires en 1992, el principal aporte doctrinario en América Latina sobre el tema.

Para Fernández Sessarego ${ }^{26}$ la identidad personal se presenta como un primordial interés existencial que merece tutela jurídica. Es, por ende, una situación jurídica por la cual el sujeto tiene el derecho a ser representado fielmente en su protección social. Teniendo el sujeto el derecho a que se le conozca y defina de acuerdo a su verdad personal, tal como es, sin desfiguraciones, sin alteraciones, sin falseamientos, sin distorsiones o desnaturalizaciones de sus características, tanto estáticos como dinámicos, que lo distinguen de los demás en cuanto lo hacen ser el mismo y no otro. Supone, por ende, este derecho la exigencia del respeto de la propia biografía.

La identidad personal de acuerdo a la teoría del jusfilósofo peruano posee dos tipos de componentes que integran una unidad inescindible. Surge como resultado de una información genética de base que es singular y única, por lo que permite identificar biológicamente a cada ser humano sin confundirlo con otro. La clave genética y las huellas digitales son elementos que conforman la identidad estática en cuanto ella es invariable. No obstante, la identidad se complementa con un plexo de atributos, características y rasgos de la persona. Estos datos, a diferencia de los biológicos, pueden cambiar en el tiempo. Por ello, este conjunto de atributos de la persona constituye el elemento dinámico de la identidad, que se encuentra compuesto de las creencias, la cultura, los rasgos propios de la personalidad, la ocupación, la ideología, la concepción del mundo y del ser humano, entre otros. Este conjunto de características que individualizan a la persona se exteriorizan, proyectándose al mundo social y permiten a los demás identificar al sujeto en la comunidad. La identidad personal no se agota en los alcances conceptuales de lo que se suele definir como identificación, noción que no abarca los aspectos propios de la persona. La identidad personal, abarcando también la identidad sexual ${ }^{27}$, es una noción comprensiva de todas las calidades del ser humano.

Con la incorporación del derecho a la identidad personal en la Constitución peruana de 1993 se abre un nuevo capítulo en la constante evolución de los derechos de la persona en el Perú. No obstante, como afirmaba el Prof. Carlos Fernández Sessarego, si bien no fue posible que

26 Fernández Sessarego, Carlos, Derecho a la identidad personal, pág. 117.

27 Sobre el tema de la identidad sexual, en relación a la problemática del transexualismo, véase a Patti, Salvatore, "Transessualismo", en: Digesto, volumen XIX, sezione civile, Utet, IV edizione, Turín, 1999, pág. 416. Stanzione, Pasquale, "Transexualismo y sensibilidad del jurista: una relectura actualizada de la ley (italiana) 164/1982", en: Observatorio de Derecho Civil, tomo IV: La persona, Motivensa editora Jurídica, Lima, 2010, págs. 213 y ss. 
el derecho a la identidad personal fuera regulado por el Código Civil de 1984, fue introducido dentro del numeral 1 del artículo 2 de la Constitución de $1993^{28}$, por influencia suya ${ }^{29}$.

\section{La protección jurídico constitucional del derecho a la identidad: Desarrollo jurisprudencial}

La Corte Interamericana de Derechos Humanos ha señalado que la Convención Americana protege el derecho a la identidad, el cual se erige de la interpretación del derecho a la vida privada y al libre desarrollo de la personalidad, de esta manera la ha definido como "el conjunto de atributos y características que permiten la individualización de la persona en sociedad y que, en tal sentido, comprende varios derechos según el sujeto de derechos de que se trate y las circunstancias del caso" 30 . De igual manera, ha reconocido que de este derecho se desprende un derecho a la identidad de género el cual concibe como "la vivencia interna e individual del género tal como cada persona la siente, la cual podría corresponder o no con el sexo asignado al momento del nacimiento" 31 .

Así respecto al proceso de reconocimiento de la identidad de las personas trans, señala que los Estados deben considerar que, “(...) el proceso de reconocimiento de la identidad de género no debe imponer a los solicitantes el cumplimiento de requisitos abusivos tales como la presentación de certificaciones médicas o pruebas de estado civil de no casados, tampoco se debe someter a los solicitantes al sometimiento a pericias médicas o psicológicas relacionadas con su identidad de género auto-percibida u otros que desvirtúen el principio según el cual la identidad de género no se prueba, por tanto el trámite debe estar basado en la mera expresión de voluntad del solicitante."32 Asimismo, “(...) los certificados médicos, psicológicos o psiquiátricos que se suelen requerir en este tipo de procedimientos, la Corte entiende que además de tener un carácter invasivo y poner en tela de juicio la adscripción identitaria llevada a cabo por la persona, descansan en el supuesto según el cual tener una identidad contraria al sexo que fue asignado al nacer constituye una patología." ${ }^{33}$ Finalmente, “(...) no podrá requerir que se lleven a cabo intervenciones quirúrgicas totales o parciales ni terapias hormonales, esterilizaciones o modificaciones corporales para sustentar el requerimiento, para otorgar lo solicitado o para probar la identidad de género que motiva dicho procedimiento, por cuanto podría ser

28 Uno de los más notables civilistas peruanos, el Prof. Yuri Vega Mere seńala que "el afán y la pasión que puso sobre este nuevo derecho Fernández Sessarego, desconocido hasta entonces en la doctrina latinoamericana, ha sido la razón por la cual la Constitución de 1993 ha recogido expresamente este valor fundamental del ser humano, en el inciso 1 del artículo 2. A él debemos la presencia de esta nueva situación jurídica subjetiva en nuestro ordenamiento, que es el primero que la acoge en su más amplia acepción [...]": Vega Mere, Yuri, "Personas naturales: nuevas propuestas", en Walter Gutiérrez Camacho (ed.), Diez años del Código Civil peruano: balance y perspectivas, t. I, Lima: Gaceta Jurídica, 1995, pág. 54.

29 "La Constitución de 1993 tuvo también inspiraciones audaces. Por ejemplo, el moderno derecho a la identidad fue introducido por Carlos Torres y Torres Lara a iniciativa de Carlos Fernández Sessarego": Ramos Núnez, Carlos, La letra de la ley. Historia de las constituciones del Perú, Centro de Estudios Constitucionales, Lima, 2018, pág. 110.

30 Corte IDH. Opinión Consultiva OC-24/17 de 24 de noviembre de 2017. Identidad de género, e igualdad y no discriminación a parejas del mismo sexo. Párr. 90.

31 Corte IDH. Opinión Consultiva OC-24/17 de 24 de noviembre de 2017. Párr. 94.

32 Corte IDH. Opinión Consultiva OC-24/17 de 24 de noviembre de 2017. Párr. 129.

33 Corte IDH. Opinión Consultiva OC-24/17 de 24 de noviembre de 2017. Párr. 130. 
contrario al derecho a la integridad personal contenido en el artículo 5.1 y 5.2 de la Convención Americana." 34

Aunado a ello, en anteriores pronunciamientos de naturaleza contenciosa como son los casos Atala Riffo y Niñas vs. Chile (2012), Duque vs. Colombia (2016) y Flor Freire vs. Ecuador (2016), ha dejado claro que la orientación sexual y la identidad de género de las personas, son categorías protegidas por Convención.

En Perú actualmente no existe una ley específica de protección del derecho a la identidad de las personas trans, pero lo que sí existe es la protección constitucional. En efecto, la Constitución Política del Perú regula en su artículo 2 que: "Toda persona tiene derecho: 1. (...), a su identidad (...)”. Respecto a este derecho, el Tribunal Constitucional del Perú ha desplegado un desarrollo jurisprudencial bajo tres sentencias de gran relevancia para el análisis del tema.

Este desarrollo se dio inicio en 2006 con el caso Karen Mañuca Quiroz Cabanillas, el cual consideramos el antecedente más importante en la materia, dado que, en atención a la correlación entre los derechos fundamentales y la dignidad humana, por primera vez se otorga un contenido al derecho a la identidad personal como elemento esencial para garantizar una vida digna $^{35}$. En esta sentencia además se define al sexo del individuo, como aquel compuesto por diversos elementos, incluyendo el psicológico y social. En línea con ello agrega que "al momento de nacer la persona solo se toma en cuenta el sexo anatómico, ya que la personalidad del recién nacido, que expresará su identidad, recién comenzará a desarrollarse.”36

A través de esta sentencia se define el derecho a la identidad como "El derecho que tiene todo individuo a ser reconocido estrictamente por lo que es y por el modo cómo es. Vale decir, el derecho a ser individualizado conforme a determinados rasgos distintivos, esencialmente de carácter objetivo (nombres, seudónimos, registros, herencia genética, características corporales, etc.) y aquellos que se derivan del propio desarrollo y comportamiento personal, más bien de carácter subjetivo (ideología, identidad cultural, valores, reputación, etc.)"37

Con esto se evidencia que el Tribunal Constitucional asume una postura sobre el sexo de las personas que va más allá del aspecto únicamente biológico, considerando también los elementos psicosociales en su composición y que éste se desarrolla a lo largo de la vida en línea con la personalidad de cada uno, aunque no llega a incluirlo en la clasificacion como un componente subjetivo o dinámico de la identidad. Cabe señalar que en esta sentencia se admite el cambio de nombre de la demandante, en atención a que lo solicitado se restringió solo a ese extremo.

Seguidamente, en 2014 con el caso Pamela Estela Mendoza Moreno, el Tribunal Constitucional adopta una posición estrictamente biologicista sobre el sexo de las personas y sostiene que, "Para el Derecho entonces el sexo viene a ser el sexo biológico, el sexo cromosómico o genético instaurado en el momento de la fecundación del óvulo por el espermatozoide, que determina el sexo femenino o masculino: cromosomas XX (femenino), cromosomas XY (masculino). La diferencia entre los sexos responde, pues, a una realidad extrajurídica y biológica

34 Corte IDH. Opinión Consultiva OC-24/17 de 24 de noviembre de 2017. Párr. 146.

35 Perú. Tribunal Constitucional. Sentencia del Expediente nro. 2273-2005-PA/TC, de 20 de abril de 2006, fundamento jurídico 7.

36 Perú. Tribunal Constitucional. Sentencia del Expediente nro. 2273-2005-PA/TC, de 20 de abril de 2006, fundamento jurídico 15.

37 Perú. Tribunal Constitucional. Sentencia del Expediente nro. 2273-2005-PA/TC, de 20 de abril de 2006, fundamento jurídico 21 . 
que debe ser constitucionalmente respetada por fundarse en la naturaleza de las cosas (artículo 103 de la Constitución), y en tanto que la ciencia aporta que el sexo cromosómico no se puede cambiar, el sexo es indisponible para el individuo. ${ }^{38}$

Como podemos advertir, en esta sentencia se asume la doctrina de la indisponibilidad del sexo de las personas, considerando que este tiene un carácter objetivo dentro de la clasificación realizada en la sentencia anterior, en la cual no se llegó a establecer como un elemento dinámico. Nótese que al definir al sexo solo considera el elemento biológico, dejando de lado el componente psicosocial. Toma provecho entonces de la clasificación abierta que dejó la sentencia anterior y posiciona al sexo en el plano objetivo, debiendo quedar ello establecido en el registro civil como una exigencia constitucional. Esto trajo como consecuencia fatal, la vulneración del derecho de acceso a la justicia de las minorías trans, dado que se estableció que no procedía solicitar este tipo de reconocimiento. Recordemos que la identidad personal como un derecho fundamental basado en la dignidad de las personas, permite su exigencia de protección ante los órganos jurisdiccionales, sin embargo, a través de esta sentencia se cerró esta facultad, negando la posibilidad a las personas trans tener un documento de identidad que refleje su identidad sentida y vivida.

Finalmente, en 2016 con el caso Ana Romero Saldarriaga, el Tribunal Constitucional deja sin efecto la doctrina del fallo anterior para dar paso a una concepción mejor elaborada del derecho a la identidad en sus ambas vertientes. Señalando que, "La realidad biológica, a tenor de lo expuesto, no debe ser el único elemento determinante para la asignación del sexo, pues éste, al ser también una construcción, debe comprenderse dentro de las realidades sociales, culturales e interpersonales que la propia persona experimenta durante su existencia [...] se caería en un determinismo biológico que reduciría la naturaleza humana a una mera existencia física y ello obviaría que el ser humano es un ser también psíquico y social."39

Partiendo de ello, se reconoce la existencia de un derecho a la identidad de género, como aquel que forma parte del contenido constitucionalmente protegido del derecho a la identidad personal, y que define como ese "(...) conjunto de vivencias que denotan una expresión propia del ser humano y que le permite distinguir de otras personas. La forma en que ella decide no seguir los patrones convencionales que, dentro de las prácticas sociales, permiten identificar a una persona como "hombre" o "mujer", es, ineludiblemente, un aspecto esencial de la manera en que ha decidido desarrollar su vida, y que, en ese sentido, merece tutela constitucional al formar parte de su identidad." 40

Como consecuencia de este último fallo constitucional, el reconocimiento del derecho a la identidad de las personas trans viene siendo atendido por la judicatura ordinaria a través del proceso sumarísimo. Máxime que también exhorta al Estado peruano a adoptar las medidas legislativas que fueren necesarias para asegurar a estas minorías el goce y ejercicio de su derecho a la identidad en condiciones de igualdad, lo que no se ha logrado hasta la fecha. Por ende, se continúa sometiendo a las personas trans a un proceso judicial para el reconocimiento de su

38 Perú. Tribunal Constitucional. Sentencia del expediente nro. 0139-2013-PA/TC de 18 de marzo de 2014, fundamento jurídico 5 .

39 Perú. Tribunal Constitucional. Sentencia del expediente nro. 6040-2015-PA/TC de 21 de octubre de 2016, fundamento jurídico 13.

40 Perú. Tribunal Constitucional. Sentencia del expediente nro. 6040-2015-PA/TC de 21 de octubre de 2016, fundamento jurídico 14 . 
identidad, que si bien se desarrolla en la vía sumarísima, de todas maneras implica un tiempo de espera considerando la carga procesal, la decadencia del sistema judicial peruano y sobre todo un corto conocimiento de nuestros jueces en materia de diversidad. Asimismo, dada la actividad probatoria de todo proceso judicial y la falta de claridad de la sentencia constitucional, en cuanto a los requisitos para su reconocimiento o la viabilidad de enmarcarlo en el principio de la autodeterminación, puede poner en peligro otros derechos fundamentales como la integridad física y la igualdad ante la ley.

Con esta última sentencia del Tribunal Constitucional peruano, vemos como el desarrollo de la jurisprudencia constitucional ha conducido al reconocimiento de un nuevo derecho, como consecuencia de una interpretación evolutiva de la Constitución y en amparo del artículo 3 de la misma. Esto con la finalidad de proteger los derechos constitucionales de aquellos grupos minoritarios que no se encontraban en la mirada del debate del constituyente de 1993 y que también constituyen derechos humanos como ha sido reconocido por la Corte Interamericana. Por ello, la labor interpretativa del Tribunal Constitucional ocupa una función de vital importancia para la protección de los derechos, en atención a que la Constitución es una norma de mínimos. En ese sentido, consideramos que el avance en la materia es neto, en donde hemos pasado de un criterio constitucional estrictamente biologicista a uno centrado en la diversidad de la persona como ser psíquico y social.

Podemos señalar que la problemática peruana actual ya no se centra en lograr el reconocimiento del derecho sino en la forma y alcances de este reconocimiento. La sentencia señalada no llega a elaborar una doctrina completa basada en la autodeterminación, por lo que quedan dudas al momento de su aplicación a los casos concretos, es decir, si se trata de un modelo constitucional basado en la autodeterminación o la heteroasignación. Criterio que será de vital importancia tener claro en atención a los efectos que pueden recaer sobre las personas trans en uno u otro caso. Considerando que por la autodeterminación primará la decisión libre e informada de la persona solicitante, mientras que por la heteroasignación la decisión de la persona deberá estar acompañada de pruebas sobre su identidad (diagnósticos médicos, modificaciones corporales, entre otros). Siendo tarea de los jueces ordinarios su interpretación, la que consideramos deberá realizarse también a las luces del criterio interpretativo adoptado por la Corte Interamericana de Derechos Humanos en la reciente Opinión Consultiva OC-24/17.

De esta manera, es necesario entender la importancia del oportuno reconocimiento de la identidad de las personas trans sin que se presenten obstáculos para ello, en tanto que, recordemos se trata de una población minoritaria históricamente discriminada, que para incluirse en la sociedad trata de invisibilizar su apariencia trans a través de cambios físicos que afectan su salud. Se ven obligados, muchas veces, a ir en contra de sus más profundos deseos de cómo llevar su propio cuerpo, sometiéndose a tratamientos médicos e incluso operaciones que deben solventar ellos mismos para encajar en las categorías binarias mujer/hombre y poder ser aceptados en una sociedad que rechaza lo diverso. Pese a todo ello, la gran mayoría no logrará esa aceptación anhelada, de ahí que vean dificultada su inclusión y el efectivo ejercicio de sus derechos como personas. La discriminación se presenta como barrera para que este grupo minoritario pueda ejercer en igualdad de oportunidades sus derechos. El acceso a la salud o al mercado formal de trabajo como principales derechos negados a este grupo que los reduce a condiciones precarias de vida, cuya supervivencia en su mayoría sobretodo de las mujeres trans se asienta en el ejercicio de 
la prostitución y con ello padecer un doble rechazo social en todos los ámbitos. Esto se confirma con la reciente encuesta sobre colectivo LGBT aplicada en Perú ${ }^{41}$, por la cual 4 de cada 10 encuestados respondieron que no estarían dispuestos a contratar a una persona trans, asimismo los resultados mostraron que la población LGBT es una de las más discriminadas en el Perú.

En ese sentido, el reconocimiento del derecho a la identidad de género se muestra como un logro sustancial, en tanto que constituye el reconocimiento constitucional de este grupo minoritario, su existencia, y que obliga su atención por parte de los poderes públicos, a través de políticas y normativa que logre su inclusión social y el efectivo ejercicio de sus derechos. Por otro lado, poder tener en las manos un documento de identidad que refleje su identidad sentida y vivida, refuerza el poder ejercitar los derechos y exigir también su respeto conforme a su condición. Siendo necesario y consideramos es una tarea pendiente del Tribunal Constitucional o de la legislación que se elabore, el establecer el criterio del reconocimiento, el cual debe considerar la autodeterminación de la persona en su diversidad, sin la exigencia de requisitos abusivos que vulneren derechos, perpetúen su patologización u obstaculicen su oportuno reconocimiento.

\section{Las medidas adoptadas por el Estado peruano durante la pandemia del Covid-19 y su impacto en el derecho a la identidad}

El pasado 2 de abril, en el marco de las medidas implementadas por el gobierno peruano para la lucha contra el Covid-19, se publicó el Decreto Supremo N 057-2020-PCM por el cual se incorporó el numeral 3.8 al artículo 3 del Decreto Supremo N 051-2020-PCM sobre Prórroga del Estado de Emergencia Nacional. Esta disposición señaló que "Para la adquisición de víveres o productos farmacéuticos, solo está permitido el desplazamiento de una persona por núcleo familiar. Los días lunes, miércoles y viernes únicamente podrán transitar personas del sexo masculino y los martes, jueves y sábados las personas del sexo femenino. Asimismo, el día domingo, la inmovilización social obligatoria es para todos los ciudadanos en el territorio nacional durante todo el día. Para la aplicación y control de la presente disposición, queda prohibido cualquier tipo de discriminación.”

En ese sentido, nos llevó a preguntarnos ¿qué pasa con las personas trans? Como hemos visto en el desarrollo jurisprudencial en Perú hemos llegado al reconocimiento del derecho a la identidad de género y que esto se vea reflejado en el documento nacional de identidad, sin embargo queda pendiente aún definir la forma y alcances de dicho reconocimiento, por lo que su aplicación práctica todavía presenta muchas deficiencias, producto de ello es que gran parte de estas minorías trans aún no vea reconocido de manera oficial su sexo sentido y vivido en el documento de identidad y, por ende, no reciban un trato jurídico como el género con el que se identifican, sin estigmatizarlos, discriminarlos o sancionarlos por ello.

La referida disposición contenía en la parte final del primer párrafo: "queda prohibido cualquier tipo de discriminación”, a la que se sumó la declaración del Presidente de la República, así como las declaraciones de algunos ministros que respaldaron la posición estatal, de que no se verificaría el sexo que figura en el documento nacional de identidad sino mediante la apariencia de la persona, lo que expresa su verdad existencial. Sin embargo, la realidad nos mostró la otra

41 II Encuesta nacional de Derechos Humanos: Población LGBT, aplicada en noviembre de 2019. 
cara de la moneda y a partir de la puesta en marcha de esta medida y durante los 8 días de su vigencia fuimos testigos, a través de los noticieros y redes sociales, de los abusos cometidos por la Policía Nacional. En los cuales se les detenía a las personas trans en la calle para solicitarles el documento de identidad y se les juzgaba por el sexo ahí consignado pese a que su apariencia indicaba lo contrario, también la imposición de castigos como ponerlos a realizar ejercicios físicos, pronunciar frases como "quiero ser hombre" hacia las mujeres trans, entre otras vejaciones seguidas de burlas en un claro atentado a su dignidad humana. Estos actos de discriminación representan una violación a los derechos humanos, que vulneraban el derecho al libre tránsito, incluso dentro de los días que podían hacerlo de acuerdo a su apariencia, ocasionándoles intimidación, un claro obstáculo en el ejercicio de sus derechos.

Esta medida fue dejada sin efecto a través del Decreto Supremo 064-2020-PCM, publicado el 10 de abril de 2020. No obstante, los hechos nos revelan que en la sociedad peruana y en las propias autoridades existe un alto rechazo a las minorías trans, lo que se traduce en la desigualdad y discriminación que ya venían sufriendo a lo largo de la historia y que se acentúan en situaciones de emergencia con la restricción de derechos fundamentales.

\section{La reacción de los organismos internacionales de Derechos Humanos y autoridades nacionales}

Sobre los diferentes hechos de violación de derechos humanos que se vienen suscitando en los Estados, los organismos internacionales de Derechos Humanos emitieron una serie de pronunciamientos en pro del respeto de los Derechos Humanos de los grupos de especial vulnerabilidad como son la población LGBTI. Tal es así que la Corte Interamericana de Derechos Humanos, mediante la declaración 1/20, de 9 de abril, instó a los Estados a abordar la problemática de la pandemia con perspectiva de derechos humanos y respetando las obligaciones internacionales. A su vez, la Comisión Interamericana de Derechos Humanos, mediante Resolución 1/2020 sobre Pandemia y Derechos Humanos en las Américas, de 10 de abril, señala la necesidad de prestar atención al impacto que tienen las medidas de emergencia frente a la pandemia, en los derechos humanos de grupos históricamente discriminados, como es el caso de las personas trans.

En la misma línea, la Comisión emitió el Comunicado de Prensa de 20 de abril de 2020, donde manifestó su preocupación en razón de que estas medidas puedan conllevar riesgos para los derechos de las personas LGBTI y derivar en actos de discriminación y violencia, poniendo de ejemplo el caso peruano y panameño. En atención a que la policía y otras fuerzas de seguridad de los Estados de la región comparten las mismas actitudes y prejuicios contra personas LGTBI que prevalecen en la sociedad en general. Llamando a los Estados a adoptar políticas de sensibilización dirigidas a las fuerzas del orden público y a las autoridades judiciales en materia de identidad y expresión de género, que tomen en cuenta que las personas trans y de género diverso, frecuentemente, no cuentan con un documento de identificación personal que refleje de manera adecuada su identidad y/o expresión de género.

Es importante agregar también que a través de la Sentencia del caso Azul Rojas Marín vs. Perú, recientemente se ha condenado al Estado peruano por violación de los derechos a la libertad e integridad personal, a la vida privada, a no ser sometido a tortura, a las garantías 
judiciales y a la protección judicial. Azul Rojas Marín es una mujer trans, que el 25 de febrero de 2008 durante la noche, se dirigía a su casa cuando fue detenida arbitrariamente por agentes de la Policía Nacional, quienes la obligaron a subir al vehículo policial bajo golpes e insultos, posteriormente en la Comisaría fue desnudada forzosamente, golpeada, torturada y finalmente violada sexualmente por vía anal con una vara policial. En esta sentencia la Corte Interamericana de Derechos Humanos concluye que "En la sociedad peruana existían y continúan existiendo fuertes prejuicios en contra de la población LGBTI, que en algunos casos llevan a la violencia [...] La violencia en algunas ocasiones es cometida por agentes estatales, incluyendo efectivos de la policía nacional y del serenazgo, tal como se alega que ocurrió en el presente caso.” ${ }^{2}$

Efectivamente, lo concluido en esta reciente sentencia es un claro reflejo de la realidad que viven día a día las personas trans y en general la población LGBTI en el Perú y que muchas veces suele quedar invisibilizada. Con ello también se corrobora los hechos sucedidos durante el periodo de vigencia del Decreto Supremo 057-2020-PCM de 2 de abril, con los abusos y la discriminación perpetrada por la Policía Nacional. Siendo necesaria la urgente implementación de las medidas impuestas al Estado peruano, dentro de las cuales se destaca "[...] adoptar un protocolo de investigación y administración de justicia durante los procesos penales para casos de personas LGBTI víctimas de violencia; crear e implementar un plan de capacitación y sensibilización sobre violencia contra las personas LGBTI a los agentes estatales; diseñar e implementar un sistema de recopilación y producción estadística de violencia contra personas LGBTI; eliminar el indicador de erradicación de homosexuales y travestis de los Planes de Seguridad Ciudadana de las Regiones y Distritos del Perú. ${ }^{43}$

Esta problemática también fue advertida por la Defensoría del Pueblo, a través del Informe 12-2020-DP, de 9 de abril, sobre situación de personas de especial protección a propósito de la declaratoria de emergencia sanitaria, en el cual menciona cómo estas medidas adoptadas han ocasionado afectaciones a los derechos a la integridad e identidad de las personas LGBTI. Tal es así que reitera la recomendación realizada al Congreso de la República referida a la aprobación de una ley específica en la materia y la realización de capacitaciones del personal de la Policía Nacional, en temas de igualdad y no discriminación por motivos de orientación sexual e identidad de género de las personas LGBTI. Cabe señalar que la Defensoría del Pueblo ha venido recomendando estas medidas desde el 2016, a través del Informe Defensorial nro. 175 y del Informe de Adjuntía 007-2018-DP/ADHPD.

\section{Tratamiento de la justicia ordinaria sobre los casos de reconocimiento de la identidad de las personas trans}

De acuerdo al último fallo del Tribunal Constitucional peruano, como se señaló líneas arriba, el conocimiento de las causas sobre reconocimiento de la identidad de las personas trans se encuentra a cargo de los jueces ordinarios a través del proceso sumarísimo. Siendo que recientemente el Poder Judicial peruano, a través de su máximo ente el Consejo Ejecutivo, demostró que dentro de esta institución que tiene a cargo uno de los procesos más importantes

42 Corte IDH. Caso Azul Rojas Marín vs. Perú. Fondo, Reparaciones y Costas. Sentencia de 12 de marzo de 2020. Párr. 51.

43 Corte IDH. Caso Azul Rojas Marín vs. Perú. Puntos resolutivos nro. 13-16. 
para el reconocimiento como sujetos de derecho de las personas trans, existe todavía una postura discriminatoria sobre este grupo minoritario y, en general, sobre la población LGTBI.

Se trata de la actualización de las Reglas de Brasilia, que se dieron como consecuencia de la XIX Cumbre Judicial Iberoamericana en el 2018. Las Reglas de Brasilia se adoptaron por primera vez en el marco de la XIV Cumbre Judicial Iberoamericana realizada del 4 al 6 de marzo de 2008, donde se aprobó el documento denominado "Acceso a la Justicia de las Personas en Condición de Vulnerabilidad" o también llamadas Reglas de Brasilia. Se adoptaron con la finalidad de garantizar y facilitar el acceso universal a la justicia sin distinción. En ese sentido, a través de su actualización en 2018, se incorporó dentro del concepto de personas en situación de vulnerabilidad (regla 3), aquellas por razón de su orientación sexual e identidad de género. Asimismo, como causa de vulnerabilidad, la orientación sexual e identidad de género (regla 4).

En ese sentido, las Reglas de Brasilia, bajo esta actualización, considera a la orientación sexual e identidad de género una condición de vulnerabilidad para el acceso al sistema de justicia cuando por este motivo las personas se vean impedidas o restringidas de ejercer sus derechos ante dicho sistema. Sobre estas disposiciones, el Consejo Ejecutivo del Poder Judicial del Perú, a través de las Resoluciones Administrativas nro. 11-2020-CE-PJ y 002-2020-CE-P, publicadas en el Diario El Peruano el 17 de julio del 2020, consideró adherirse a la actualización con excepción de la regla 4 "en el extremo que constituye como causa de vulnerabilidad la orientación sexual e identidad de género". Dentro de todo ello, una de las cuestiones más resaltantes fue el voto singular del Consejero y Juez Supremo Javier Arévalo Vela en la cual expresó que biológicamente solo es admisible la existencia del género masculino y femenino, y que la orientación sexual en condiciones normales solamente puede ser heterosexual.

Posteriormente, la Presidencia de la Comisión Permanente de Acceso a la Justicia de Personas en Condición de Vulnerabilidad, solicitó la reconsideración de dicha decisión a los Consejeros del Poder Judicial el cual fue declarado fundado. Por lo que actualmente el Consejo Ejecutivo del Poder Judicial ha dispuesto la aplicación, sin excepción alguna, de la actualización de las Reglas de Brasilia sobre Acceso a la Justicia de Personas en Condiciones de Vulnerabilidad. Como vemos, estos hechos son una clara muestra de cuál es el criterio que impera en los magistrados del órgano más importante del Poder Judicial, y así también se replica en diversos jueces a nivel nacional, un riesgo para que la población LGTBI no vea afectado su derecho de acceso a la justicia sin discriminación.

Partiendo del criterio de algunos Jueces Supremos en el Perú, como hemos señalado en las líneas precedentes, también es importante conocer, a través de la jurisprudencia ordinaria, bajo qué criterios se vienen resolviendo los pedidos de cambio de la mención del sexo en los registros. Resulta importante determinar cómo se viene protegiendo el derecho a la identidad en las instancias judiciales peruanas, a efectos de tener una idea más clara sobre la afectación de este derecho por la pandemia del Covid-19.

Así tenemos la Sentencia del Expediente nro. 05684 del Segundo Juzgado Civil de Paucarpata - Arequipa, de fecha 5 de enero de 2018 sobre cambio de sexo. En esta sentencia el magistrado ampara la pretensión sobre cambio de sexo solicitada por A.A.V.G., donde analiza la documentación aportada por el demandante consistente en: certificado psicológico donde se acredita el trastorno de identidad de género, certificado médico por el cual se acredita la intervención quirúrgica de extirpación de mamas, extracción de útero y aparato reproductor 
femenino total. Sostiene que "(...) se le aprecia al accionante con todos los rasgos físicos exteriores de un varón, acreditándose una vez más que se trata de un caso de transexualismo." 44 Asimismo, hace referencia a la declaración del demandante en audiencia y dos testimoniales que corroboran ello, para concluir que "(...) al amparo de los derechos fundamentales a la identidad de la persona $y$ de sexo, fundamentalmente dinámica en ambos casos; en concordancia con el derecho fundamental a la libertad, desarrollo y bienestar de la persona, protegiendo el proyecto de vida en este caso de una persona transexual, es que consideramos pertinente atender la pretensión incoada" ${ }^{45}$.

A través de esta sentencia advertimos el reconocimiento del derecho a la identidad de género. Sin embargo, ello es como consecuencia de la valoración de los elementos probatorios referidos al diagnóstico médico y las modificaciones corporales practicadas, lo que es contrario a lo señalado por la Corte Interamericana. Lo que nos lleva a preguntarnos si se reconocería o no este derecho a una persona trans que no se ha sometido a estos cambios físicos. Esta es una muestra de cómo se viene reconociendo el derecho a la identidad de las personas trans en el Perú hasta la fecha. Se continúa sometiendo a las personas trans a un proceso judicial para el reconocimiento de su identidad. Además, tener que reunir una serie de requisitos para probar la identidad, como lo hemos visto en el caso citado, y lo que es valorado por el magistrado para reconocer el derecho.

Estos medios probatorios sobre la identidad de género suponen un sacrificio, donde entran en juego derechos fundamentales a la integridad física, libre desarrollo de la personalidad, igualdad y no discriminación. Pensemos que durante estos momentos en que todavía se vive la pandemia a nivel mundial y también en el Perú se continúen exigiendo estos requisitos para reconocer un derecho tan importante como es el derecho a la identidad. Definitivamente estas exigencias se convierten en obstáculos para acceder al reconocimiento de este derecho donde las desigualdades se incrementan porque la mayoría de personas trans en el Perú se encuentra viviendo en condiciones precarias, siendo que solamente pueden alcanzar a satisfacer sus necesidades alimenticias. Y dentro de esta desigualdad también existe un fuerte componente de género, y es que las mujeres trans son quienes vienen padeciendo en mayor medida la falta de atención del Estado. Estamos hablando de personas a quienes no se les reconoce como sujetos de derecho mientras no se sometan a esos requisitos. Por lo que es tarea de los jueces ordinarios realizar una interpretación del criterio a aplicar en los casos concretos a las luces del criterio interpretativo adoptado por la Corte Interamericana de Derechos Humanos en la Opinión Consultiva OC-24/17.

Por otro lado, tenemos otra sentencia expedida por el juzgado especializado en lo constitucional de Lima $^{46}$, por la cual se ordenó al RENIEC ${ }^{47}$ la elaboración de un procedimiento administrativo para el reconocimiento de la identidad de género de las personas trans e intersex. El magistrado llega a señalar cuáles deben ser las exigencias máximas a requerir para poder

44 Perú. Corte Superior de Justicia de Arequipa. Sentencia del Expediente 05684-2016, de 5 de enero de 2018, emitida por el Segundo Juzgado Civil del Módulo Básico de Justicia de Paucarpata, f. 4.

45 Perú. Corte Superior de Justicia de Arequipa. Sentencia del Expediente 05684-2016, de 5 de enero de 2018, emitida por el Segundo Juzgado Civil del Módulo Básico de Justicia de Paucarpata, fj. 4.

46 Perú. Corte Superior de Justicia de Lima. Sentencia del Tercer Juzgado Constitucional Transitorio de Lima, en Proceso de amparo, de fecha 30 de julio de 2020.

47 Registro Nacional de Identificación y Estado Civil, actúa como parte demandada en los procesos de cambio de la mención del sexo en los registros. 
realizar el trámite, el cual debe ser rápido y de preferencia gratuito, no debe exigir intervenciones quirúrgicas, tratamientos hormonales e incluso admitir una categoría adicional a masculino o femenino. De tal manera, que sea exigible únicamente el consentimiento libre e informado del solicitante, en una clara muestra de atención a lo dispuesto por la Corte Interamericana de Derechos Humanos en su Opinión Consultiva OC-24/17. Cabe señalar que a través de esta sentencia se declara el estado de cosas inconstitucional, específicamente una "omisión inconstitucional", ante la inexistencia de un procedimiento que permita el cambio de nombres, sexo e imagen en el documento de identidad conforme a los parámetros seńalados por la Corte Interamericana. Reconoce que, en virtud de ello, existe una vulneración sistemática al derecho a la identidad y al libre desarrollo de la personalidad.

Esta sentencia es una muestra de que la justicia peruana está tomando conciencia sobre las necesidades de estas poblaciones minoritarias que durante años han venido sufriendo la discriminación y vulneración de sus derechos fundamentales en el Perú. Sin embargo, no se trata de una sentencia firme dado que ha sido apelada por el RENIEC, por lo que la causa será conocida por la Sala Superior de la Corte de Justicia de Lima. Pese a ello es importante reconocer que se trata de un avance importante en materia de derechos fundamentales de grupos minoritarios históricamente desplazados, que ahora queda en manos de la Sala Superior la decisión.

\section{Conclusiones}

Es necesario reconocer que los derechos de las personas LGBTI son derechos humanos, que esta población históricamente discriminada también sufre las consecuencias del sistema sexo-género, a través de la cual son violentados u obstaculizados en el ejercicio de sus derechos por apartarse de los patrones socialmente construidos sobre la genitalidad de las personas. De no aceptar ni comprender que las personas son diversas, que son idénticas a sí mismas, que en atención a la libertad como seres con dignidad pueden proyectar su vida conforme a sus más profundas aspiraciones, entendiendo que la identidad es parte del proyecto de vida. El no reconocimiento de sus derechos humanos, es negarle su condición de seres con dignidad, de establecer diferencias por su identidad diversa, cuando la dignidad de las personas está por encima de las características que pueda tener cada persona. Recordemos que la dignidad es el fundamento de los derechos humanos y que las constituciones políticas adoptan tanto como principio y como derecho subjetivo, en ese sentido los derechos fundamentales tienen un doble carácter siendo uno de ellos que impone a los poderes públicos el deber positivo de proteger ese derecho, lo que hasta ahora no se ha realizado respecto al derecho a la identidad personal.

Tampoco es suficiente la mera positivización del derecho, sino que esto debe involucrar también su efectivización en la realidad, para lograr la igualdad real y material, la que se traduce en la igualdad de oportunidades para su acceso y su disfrute por parte de todas las personas, a través de las disposiciones normativas y políticas públicas enfocadas en ello. Es momento de preocuparnos por esa parte tan importante que falta desarrollar que es la igualdad real y material, de lo contrario estaríamos admitiendo que los derechos solo pueden ser ejercidos por una parte y que la otra, por sus características, no pueden acceder a ellos, vulnerando el fin supremo de todos los derechos fundamentales que es el reconocimiento de la dignidad de las personas por el hecho de ser personas, independientemente de cualquier característica. 
Los hechos ocurridos durante los 8 días de vigencia del Decreto Supremo 057-2020PCM, son una muestra clara de cómo entiende y responde la sociedad peruana y las autoridades ante las personas trans: con violencia y discriminación. Hechos que durante mucho tiempo se han encontrado invisibilizados y que sigue siendo así en la mayoría de casos, pues son pocos quienes se atreven a denunciar, precisamente porque quienes deberían defenderlos también son quienes violan sus derechos, y aquí nos remitimos también al triste caso de Azul Rojas Marín. Esta problemática social se intensifica en tiempos de emergencia como en el que nos encontramos actualmente producto del Covid-19 con la limitación de algunos derechos fundamentales. Es por ello que antes de adoptar las medidas pertinentes para la contención del virus, se consideren las consecuencias y prevean los mecanismos necesarios para evitar un grave impacto no solo en los grupos LGBTI, sino también las mujeres, las personas con discapacidad, y en general quienes integran los grupos con mayor vulnerabilidad. Esto es, como lo ha señalado la Comisión Interamericana de Derechos Humanos, aplicar un enfoque de derechos humanos.

En la misma línea, la falta de desarrollo legislativo en la materia y mientras no se tenga reconocida la identidad sentida y vivida, constituye una negación al derecho a la identidad de las personas trans, estamos negando esta realidad, la existencia de estas minorías, que merecen la tutela oportuna de sus derechos. Asimismo, mantener vigente los procesos judiciales para el reconocimiento de un derecho tan importante como es el derecho a la identidad, bajo las exigencias que se vienen valorando actualmente por los jueces ordinarios complican que las personas trans puedan acceder a su reconocimiento. Se muestran como obstáculos que incrementan las desigualdades durante la pandemia del Covid-19. esta situación debe servir para replantearnos la necesidad de una ley específica en la materia, que les reconozca un proceso basado en el consentimiento libre e informado del solicitante, sin la exigencia de requisitos invasivos y abusivos como certificaciones médicas o psicológicas, o de operaciones quirúrgicas o tratamientos hormonales que son contrarios a la integridad personal. La naturaleza del proceso de reconocimiento debe ser administrativo o notarial libre de escrutinio y validación externa de la identificación sexual y de género de la persona que lo solicita, como lo ha indicado el máximo tribunal de garantía de los derechos humanos en la región. 